\title{
Rapid response to artificial selection on flower size in Phlox
}

\author{
G Lendvai and DA Levin \\ Section of Integrative Biology, University of Texas at Austin, Austin, TX 78712, USA
}

Quantitative characters are often said to evolve rather slowly, taking many generations to exhibit appreciable differences among populations. We tested this notion experimentally by performing bi-directional selection on corolla diameter of plants from a wild population of Phlox drummondii for three generations. By monitoring flower size, tube length and stigma-anther proximity of flowers, we obtained the direct and indirect responses to selection, and calculated genetic correlations, realized and narrow sense heritabilities using offspring-mother regression. Realized heritability of flower size was high (0.83), whereas genetic correlations among traits were weak or not significant. The per-generation average of the response in corolla diameter was about $5 \%$. We found that $P$. drummondii has a great capacity to respond rapidly to selection, and this capacity may be in part responsible for the observed high degree of differentiation within the species. We also concluded that rapid evolution of morphological floral traits is possible.

Heredity (2003) 90, 336-342. doi:10.1038/sj.hdy.6800249

Keywords: bi-directional selection; genetic correlations; flower size; rate of evolution; annual Phlox

\section{Introduction}

Changes in floral characters have been involved in the diversification of many taxa at both inter- and intraspecific level (Grant and Grant, 1965; Stebbins, 1974; Reeves and Olmstead, 1998; Harrison et al, 1999). These modifications are likely to represent adaptive responses (Proctor et al, 1996; Mazer and Meade, 2000), and are frequently associated with speciation events as in the genus Lapeirousia (Goldblatt and Manning, 1996).

Adaptive changes are commonly regarded as occurring gradually over many generations (Fisher, 1930; Mayr, 1970). In recent years, however, it has become apparent that rates of evolution may be surprisingly rapid (Macnair, 1990). The best understood examples of rapid evolution of single traits are cases of tolerance to herbicides and heavy metals in plants. An increase in herbicide tolerance has been observed in many North American weeds over only a few decades (Davies, 1993). Evolution of zinc-tolerant populations of Deschampsia caespitosa and Anthoxanthum odoratum under electricity pylons has occurred in only 17 years (Al-Hiyali et al, 1990). In Germany, zinc-tolerant populations of $A$. capillaris evolved from nontolerant ones in a mere 3 years (Ernst et al, 1983).

Phylogenetic evidence also suggests the occurrence of rapid evolution in certain situations. On the Macaronesian Islands, for example, the genus Echium has diversified into 21 species with a wide range of habitat preferences, life-histories, and morphologies, while the continental sister lineage produced only two relatively similar herbaceous species during the same time (Böhle

Correspondence: G Lendvai, Section of Integrative Biology, University of Texas at Austin, Austin, TX 78712, USA.

E-mail: g.lendvai@mail.utexas.edu et al, 1996). Evolution of nectar spurs in Aquilegia led also to rapid speciation in the spurred-clade, while its sister lineage evolved into a single species (Hodges and Arnold, 1995).

Floral traits usually play a key role in rapid diversification, as their modification can easily lead to reproductive isolation and species formation (Grant, 1994; Levin, 2000). All else being equal, species with high potential for rapid response to selection on such traits are likely to differentiate into more incipient species and have a greater number of successful descendants than species with low potentials for rapid evolution. Yet, relatively little is known about the evolutionary rates of such floral characters (but see Galen, 1996).

Is floral evolution necessarily a slow and gradual process taking thousands of generations, or do plants have the potential to respond rapidly to selection on floral traits over consecutive generations allowing for large-scale changes in a relatively short period of time? On theoretical grounds, floral evolution is likely to be slow because of the presence of genetic correlations among various traits, which can substantially constrain the rate and magnitude of evolutionary changes. Floral traits are likely to have been fine tuned by stabilizing selection (Conner and Via, 1993; Cresswell, 1998), and thus are expected to have relatively low genetic variation and show significantly high phenotypic and genetic correlations (Endler, 2000). However, empirical evidence does not support these considerations. In several families morphological diversity of flowers in one genus contrasts with morphological similarity in other genera that occur in a similar range of environments, such as in the pairs of Aquilegia vs Semiaquilegia (Hodges and Arnold, 1995), Dierama vs Ixia (Iridaceae) (Goldblatt, 1990), Castilleja vs Pedicularis (Scrophulariaceae) (personal observation), and Allophyllum vs Gilia (Polemoniaceae) 
(Grant and Grant, 1965). Because the age of the members of these lineage-pairs is by definition the same, these differences suggest that rate of floral evolution can vary substantially and sometimes may be surprisingly rapid.

Here we report the results of an experiment in which we studied the tempo of and constraints on flower size (corolla diameter) evolution of Phlox drummondii by artificially selecting for smaller and larger flowers. Modification of flower size has been a recurrent theme in the evolutionary diversification of Phlox at various taxonomic levels. Divergence in flower size is most prominent in the annual clade, in which $P$. cuspidata and $P$. roemeriana have the smallest $(17 \mathrm{~mm})$, and the largest flowers $(31 \mathrm{~mm})$, respectively, whereas corolla diameter of $P$. drummondii averages $26 \mathrm{~mm}$ that represents the norm of the genus (Wherry, 1955). Phylogenetic studies indicate that both $P$. cuspidata and $P$. roemeriana are derived from a $P$. drummondii-like ancestor (Ferguson et al, 1999).

In the experiment, we addressed the following questions: Can flower size of $P$. drummondii be easily modified toward that of P. cuspidata on the one hand, and toward that of $P$. roemeriana on the other? What is the degree of genetic variation of flower size? Is flower size genetically correlated with other floral traits, which can constrain its evolution?

\section{Materials and methods}

$P$. drummondii is a winter annual occurring in central Texas in open grasslands. A plant usually produces 10 50 flowers from early to mid-March till June. Flowers are pink throughout most of the range, except in the eastern part, where flowers are red. The diameter of the diskshaped face of the corolla is about $26 \mathrm{~mm}$, and is consistent within, but can vary substantially among, individuals. Flowers have a long and narrow tube in which the five stamens are included. The stigma is threelobed, and is below all stamens. Flowers are pollinated mostly by swallowtail butterflies, particularly by the pipevine butterfly (Battus philenor, Papilionidae) in our study area. The fruit is a small (3-4 mm) capsule regularly with three, occasionally four, seeds.

\section{Breeding protocol and statistical analyses}

We established an experimental population in the greenhouse by collecting 350 seedlings in the four-leaved stage from a wild pink population of $P$. drummondii near Bastrop, TX in February 1996. The variation of corolla diameter in this population $(\mathrm{SD}=2.08 \mathrm{~mm})$ is representative of the species ( $\mathrm{SD}=1.64-2.59 \mathrm{~mm}, 29$ populations). After each surviving plant produced at least 20 flowers, we measured the diameter of three randomly selected and fully open flowers. Of the 307 plants, 30 were selected with the largest and 30 with the smallest flowers, and an additional 30 plants at random as a control line. Pollen was collected from one mature flower of each plant within these groups into a small Petri dish, and applied small amounts of the thoroughly mixed pollen to at least 15 flowers on each plant. The resulting seeds were collected and stored until November, when they were planted. Germination rates were unusually low (20-30\%) despite an initial gibberellic-acid treatment to facilitate germination. During January, 1997, the seedlings were transplanted into pots containing the same growing medium. Of all seedlings, 172 survived to flowering in the up line, 65 in the down line, and 101 in the control line. As a consequence, we were unable to establish replicate populations for any line during the experiment.

Plants were randomly arranged in the greenhouse to minimize the effect of environmental variation. At flowering, we measured the flowers on each plant following the same procedure as described above. For breeding, 25 most extreme phenotypes of the two selected lines and 25 randomly chosen plants of the control line were used. For hand-pollination, seed collection, storage, planting, and plant arrangement we followed the same protocol as previously described. As earlier, germination was uneven among the lines. During the flowering period, we collected three flowers from each individual and measured the corolla diameter, tube length, and the distance between the stigma and the lowest anther with a caliper.

To obtain estimates of heritability of the latter two floral traits, we performed an additional cycle of selection with the 23 largest-flowered, 24 smallestflowered, and 21 randomly assigned control plants. We pollinated at least five flowers on each plant, and collected the matured fruits in September. From these seeds 188 plants reached flowering in 1999. Seed production and germination were very poor in the downward selected line, and only nine plants reached flowering. As before, we measured the same characters on three randomly selected flowers of each plant.

To calculate the response to selection in each generation, we used weighted selection differentials (Falconer and Mackay, 1996), because contributions of individual plants to the next generation were very heterogeneous. Using the breeder's equation $\left(R=h^{2} \times S\right.$, where $R$ is the response to selection, $S$ is the selection differential, and $h^{2}$ is the realized heritability), we calculated the realized heritability of flower size for each generation in both selected lines. To take into account environmental effects between years, we calculated response to selection as the difference between the selected line and the control line within the same generation (Lynch and Walsh, 1998). We estimated overall realized heritability as the average of the heritabilities for single generations (Falconer and Mackay, 1996). As a result of its small size, the 1999 down line was excluded from this calculation. The averaging gives a more reliable estimate of realized heritabilities than a single value based on a single generation, since fluctuations in phenotypic values due to several factors are inevitable between generations (Falconer and Mackay, 1996). Significance of response was tested by a nested mixed-model ANOVA (PROC GLM, SAS ver. 6.12) with individuals as a random factor for each line and each generation.

We also estimated narrow-sense heritabilities of corolla diameter, flower tube length and anther-stigma distance using mother-offspring regression. In this type of regression, twice the value of the regression coefficients estimates heritability with the corresponding standard errors. We regressed the mean corolla diameter of each progeny on the corolla diameter of their corresponding mother for each line and for each generation separately. The number of families varied between 18 and 30, and the number of offspring within families between 1 and 13 
Table 1 Changes in average corolla diameter and estimated realized heritabilities of the three lines of $P$. drummondii over three generations of selection

\begin{tabular}{llrcc}
\hline Year & Treatment & $N$ & $\begin{array}{c}\text { Mean }( \pm S E) \\
(\mathrm{mm})\end{array}$ & $\begin{array}{c}\text { Realized } \\
\text { heritability }\end{array}$ \\
\hline 1996 & Base & 307 & $28.67 \pm 0.15$ & - \\
1997 & Control & 101 & $30.04 \pm 0.27$ & - \\
& Up & 172 & $32.21 \pm 0.19$ & 0.53 \\
& Down & 65 & $27.76 \pm 0.31$ & 0.71 \\
& & & & \\
1998 & Control & 95 & $28.11 \pm 0.24$ & - \\
& Up & 68 & $31.90 \pm 0.29$ & 0.98 \\
& Down & 149 & $25.27 \pm 0.18$ & 1.14 \\
1999 & Control & 96 & $29.68 \pm 0.26$ & - \\
& Up & 83 & $33.74 \pm 0.31$ & 1.91 \\
& Down & 9 & $26.63 \pm 1.72$ & 0.94 \\
\hline
\end{tabular}

(Table 1). Since within-family correlation among offspring can introduce bias in estimating heritability when family sizes are different, we also examined the relationship between maternal corolla diameter and offspring number by calculating their correlation coefficients from simple linear regression. Positive correlation indicates a possible overestimation of heritability. In these analyses we used the square-root of the relative offspring number (offspring number divided by the largest offspring number in the line). In the 1997 control line, a further logarithmic transformation was necessary. To determine whether the observed changes in corolla tube length and anther-stigma distance were significantly different from zero, we used a two-sample $t$-test (PROC TTEST, SAS ver.6.12).

Phenotypic correlations were calculated from the average trait values of the 1998 and 1999 control lines pooled using Pearson product-moment correlations (PROC CORR, SAS ver.6.12), because correlation coefficients calculated separately for each generation were not significantly different ( $P>0.05$ for all pairs). Corolla tube length was log-transformed and stigma-anther distance was transformed using the formula of $\sqrt{ }(\mathrm{S}-\mathrm{A}$ distance +1$)$ to improve normality. We estimated additive genetic correlations from parent-offspring resemblance data using the following equation,

$$
r=\frac{\operatorname{cov}_{\mathrm{AB}}+\operatorname{cov}_{\mathrm{BA}}}{2 \operatorname{cov}_{\mathrm{AA}} \times \operatorname{cov}_{\mathrm{BB}}}
$$

where $\operatorname{cov}_{A B}$ is the covariance between the values of the maternal trait $A$ and offspring trait $B, \operatorname{cov}_{B A}$ is the covariance of maternal trait $B$ and offspring trait $A$, $\operatorname{cov}_{\mathrm{AA}}$ is the covariance of trait $\mathrm{A}$, and $\operatorname{cov}_{\mathrm{BB}}$ is the covariance of trait $B$ between parents and the offspring generation (Young et al, 1994; Falconer and Mackay, 1996). The approximate standard error of the estimate is given by the formula

$$
\mathrm{SE}(r)=(1 / \sqrt{2})\left(1-r^{2}\right) \sqrt{1 /\left(h_{x}^{2} h_{y}^{2}\right) \operatorname{SE}\left(h_{x}^{2}\right) \operatorname{SE}\left(h_{y}^{2}\right)}
$$

where SE refers to the standard error of the statistic (Falconer and Mackay, 1996). Since no exact parametric statistical test is available for this statistic, we used nonparametric bootstrapping to test for significance.

\section{Results}

Selection yielded substantial changes in corolla diameter in both the up and down lines (Figure 1). In the up line, flower size increased to $33.70 \mathrm{~mm}$ from the initial value of $28.87 \mathrm{~mm}$ after only three generations, a $17 \%$ increase. Although the magnitude of increase varied between generations, the difference in mean corolla diameter between the control and the up lines was significant in all generations. In the down line, flower size decreased to $25.28 \mathrm{~mm}$ from the initial $28.87 \mathrm{~mm}$ after two generations of selection. As in the up line, changes in flower size between generations varied, but were always significant.

In the control line, the initial average corolla diameter was $28.99( \pm 0.21) \mathrm{mm}$. This value varied between 30.04 and $27.63 \mathrm{~mm}$ in subsequent generations. Since these variations were most likely because of year-to-year variation in the greenhouse environment, selection differentials and response to selection for each generation were calculated using the control line as the baseline population for comparison.

\section{Heritability and genetic correlations}

The realized heritability of flower size calculated from responses to selection over two generations was 0.83 (Table 1). The estimates of narrow-sense heritability of flower size were somewhat greater (0.88) than the realized heritability values from the selection responses (Table 2), and ranged from 0.72 to 0.98 between generations and lines.

Maternal corolla diameter and offspring number were significantly negatively correlated in the up lines in 1997 $(r=-0.55, P=0.023)$ and $1999(r=-0.47, P=0.030)$, but not in $1998(r=0.01, P=0.956)$, whereas they were positively correlated in the control lines only in 1997 $(r=0.54, P=0.015)$, but not in $1998(r=-0.05, P=0.820)$ or $1999(r=0.356, P=0.135)$. The positive correlation did not affect substantially the overall estimate of narrowsense heritability of corolla diameter ( 0.88 with all three vs 0.85 with 1997 control line omitted; Table 2). Estimates of narrow-sense heritabilities of flower tube length (0.49) and anther-stigma distance (0.66) were significant only for the control line (Table 3).

As a correlated response to selection for larger corolla diameter, tube length decreased by $0.44 \mathrm{~mm}$ after one

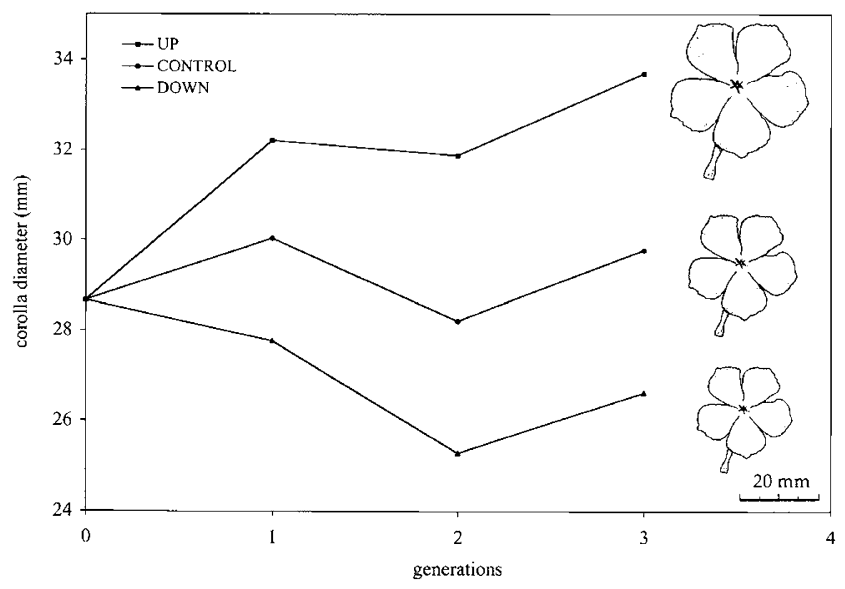

Figure 1 Response of the selected lines of $P$. drummondii to bidirectional selection on corolla diameter over three generations. 
Table 2 Regression coefficients (b), their significance values $(P)$, sample size (number of families), and estimated heritabilities $\left(h^{2}\right)$ from mother offspring regressions in three different years

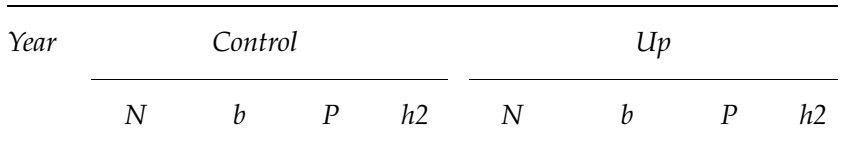

$\begin{array}{rrrrcrrrc}1997 & 101(18) & 0.472 & 0.003 & \mathbf{0 . 9 4} & 172(30) & -0.570 & 0.075 & - \\ 1998 & 95(25) & 0.264 & 0.026 & \mathbf{-} & 68(22) & 0.491 & 0.017 & \mathbf{0 . 9 8} \\ 1999 & 84(20) & 0.361 & 0.012 & \mathbf{0 . 7 2} & 71(20) & 0.417 & 0.145 & -\end{array}$

Bold values indicate significant heritability values at $P<0.05$. Regression coefficients were not significant in any year in the downward selected line.

Table 3 Regression coefficients $(b)$, significance values $(P)$, and estimated heritabilities for correlated traits from mother-offspring regressions

\begin{tabular}{|c|c|c|c|c|c|c|}
\hline & \multicolumn{3}{|c|}{ Control } & \multicolumn{3}{|c|}{$U p$} \\
\hline & $b$ & $P$ & $h 2$ & $b$ & $P$ & $h 2$ \\
\hline $\begin{array}{l}\text { Stigma-anther } \\
\text { distance }\end{array}$ & 0.329 & 0.012 & 0.66 & 0.295 & 0.164 & 0.59 \\
\hline Tube length & 0.246 & 0.022 & 0.49 & 0.355 & 0.517 & 0.71 \\
\hline
\end{tabular}

Boldface values indicate significant heritabilities at $P<0.05$ level.

generation ( $P=0.008$, PROC T-TEST SAS ver. 6.12). Anther-stigma distance, however, increased at the same time by $0.37 \mathrm{~mm}(P=0.021$, PROC T-TEST SAS ver. 6.12$)$. In contrast, two generations of selection for smaller corolla diameter resulted in highly significant decrease in both, corolla tube length $(-1.45 \mathrm{~mm}, P<0.001)$ and anther-stigma distance $(-0.59 \mathrm{~mm}, P<0.001)$.

For genetic correlations, we obtained estimates from parent-offspring resemblance using trait covariances between parents and offspring (Soltis, 1986; Young et al, 1994; Falconer and Mackay, 1996). Genetic correlations between trait pairs were all positive. The highest correlation was found between corolla diameter and flower tube length (0.53), which was also the only one being significantly different from zero. This contradicts the results of the selection experiment, because tube length had a negative indirect response to selection on flower size, and thus a negative genetic correlation was expected. The other two genetic correlations were substantially lower.

Phenotypic correlations between the three characters were calculated from the parental and offspring generations of the control line (Table 4). All values were positive and, with the exception of those involving stigma-anther distance, were significantly different from zero. In addition, the corresponding genetic and phenotypic correlations differed greatly, with the exception of that between flower size and tube length. For example, the phenotypic correlation of flower size and stigma-anther distance is about half of their genetic correlation, whereas phenotypic correlation between tube length and stigma-anther distance is almost twice as large as the genetic correlation. Only in the case of flower size
Table 4 Genetic (above diagonal) and phenotypic (below diagonal) correlations and their standard error between floral traits in the control line

\begin{tabular}{lccc}
\hline & Flower size & $\begin{array}{c}\text { Stigma-anther } \\
\text { distance }\end{array}$ & Tube length \\
\hline $\begin{array}{l}\text { Flower size } \\
\begin{array}{l}\text { Stigma-anther } \\
\text { distance }\end{array}\end{array}$ & $0.098( \pm 0.07)$ & $0.26( \pm 0.24)$ & $0.53^{*}( \pm 0.20)$ \\
Tube length $^{\mathrm{a}}$ & $0.509^{* * *}( \pm 0.06)$ & $0.399^{* * *}( \pm 0.07)$ & \\
\hline
\end{tabular}

${ }^{*} P<0.05,{ }^{* * *} P<0.001$. Genetic correlations $(r)$ were estimated from offspring-mother regressions, and are considered significant at $P<0.05$, if $2 \mathrm{SE}(r)<r$.

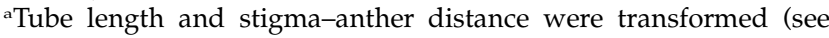

Table 5 Correlated responses to selection for larger (Up) and smaller (Down) flower sizes and their significance values (onetailed, two-sample $t$-test)

\begin{tabular}{|c|c|c|c|c|c|}
\hline & & \multicolumn{2}{|c|}{1998} & \multicolumn{2}{|c|}{1999} \\
\hline & & $\begin{array}{c}\text { Response } \\
\text { (mm) }\end{array}$ & $P$ & $\begin{array}{l}\text { Response } \\
(\mathrm{mm})\end{array}$ & $P$ \\
\hline \multirow[t]{2}{*}{ Up } & $\begin{array}{l}\text { Stigma-anther } \\
\text { distance }\end{array}$ & 0.056 & 0.384 & 0.432 & 0.021 \\
\hline & Tube length & -0.080 & 0.352 & -0.524 & 0.008 \\
\hline \multirow[t]{2}{*}{ Down } & $\begin{array}{l}\text { Stigma-anther } \\
\text { distance }\end{array}$ & -0.593 & $<0.001$ & & \\
\hline & Tube length & -1.455 & $<0.001$ & & \\
\hline
\end{tabular}

and tube length does phenotypic correlation provide an approximate estimate for the additive genetic correlation of the traits (Table 5)

\section{Discussion}

Our study represents the second multigenerational artificial selection programs on corolla diameter in a wild plant population. The first such selection program was conducted by Worley and Barrett (2000). Closely related floral characters other than corolla diameter, such as calyx diameter (Meagher, 1994) and petal area (Stanton and Young, 1994) were also shown to respond to selection for more than two generations.

In this experiment, flower size of $P$. drummondii increased by $17 \%$ in the up line within only three generations to $33.70 \mathrm{~mm}$ that is about the same size as that of the closely related $P$. roemeriana. Selection for smaller flower sizes also yielded a large response $(2.93 \mathrm{~mm})$ in only two generations bringing the selected line half-way to the P. cuspidata phenotype.

Given that their recent ancestor had flower sizes similar to that of contemporary P. drummondii, the flower size of $P$. cuspidata and P. roemeriana could have evolved from a $P$. drummondii-like ancestor in only a relatively few generations even with field heritabilities and selection differentials substantially lower than our greenhouse estimates. For example, if the magnitude of response were maintained over generations, this would have taken about eight generations for $P$. cuspidata, because the average difference in flower diameter between P. drummondii and P. cuspidata is about $9 \mathrm{~mm}$. 
Responses of similar magnitude were reported by Worley and Barrett (2000) who selected on flower area in Eichhornia paniculata. After two generations of bi-directional selection, flower size increased by $18 \%$, and decreased by $13 \%$. The estimated heritability of flower area was 0.48. In Polemonium viscosum, Galen (1996) found a $9 \%$ increase after one bout of selection on corolla flare. She predicted that populations above the timberline may have evolved in one to three generations from those at the timberline, based on the observed 15\% difference in corolla flare between the two phenotypes.

Some other reproductive traits were found to be also evolutionarily labile and readily modifiable by artificial selection in wild species. For example, petal area and pollen production exhibited rapid responses to bidirectional selection on their ratio in Raphanus satious (Stanton and Young, 1994). Petal area and pollen number increased by 18 and $4 \%$, and decreased by 12 and $4 \%$, respectively, in the selected lines. In Spergularia marina, upward selection yielded a 20 and $9 \%$ increase in anther and ovule number per flower, respectively, and downward selection a $14 \%$ decrease in anther number, but no change in ovule number within only two generations (Mazer et al, 1999). In addition, total corolla area and petal number also showed substantial correlated responses to selection on anther number.

The facility to respond to bi-directional selection suggests that $P$. drummondii species harbors a relatively high amount of genetic variation for this character. However, similarly rapid changes under field conditions can be expected only if trait heritability and intensity of selection occurring in nature are comparable to those in the greenhouse. Heritability of flower size in this population of $P$. drummondii is high under greenhouse conditions (0.88). Although heritability estimates derived from mother-offspring regression may be influenced by maternal effects, this influence is not likely to be substantial in our case, as suggested by the congruence of our estimates of realized (0.83) and narrow-sense heritabilities (0.88). This result is different from that of Schwaegerle et al (1986) whose estimate of narrow-sense heritability of flower size from half-sib analysis was about half $(0.44 \pm 0.17)$. Studies on Ipomopsis aggregata (Campbell, 1996) and P. viscosum (Galen, 1996), both Polemoniaceae, showed that field heritabilities of flower size are close to greenhouse estimates or are very high. If these findings represent a general trend, then the high evolutionary potential of $P$. drummondii could be realized under natural conditions even at moderate levels of selection intensity.

What might explain the rapid responses to artificial selection on flower size? One key to rapid responses may be a small number of loci with large phenotypic effects controlling the traits (Macnair, 1990; Falconer and Mackay, 1996; Orr, 1998). Recent studies have confirmed that several floral traits are controlled by only a few genes or quantitative trait loci (QTL) with apparently large effects (Doebley and Stec, 1993; Bradshaw et al, 1998). Unfortunately, the information at hand is not enough to assess the number of controlling loci and their contribution to the rate of the response in Phlox.

Another reason for rapid responses to artificial selection on flower size can be the absence of strong genetic correlations among floral traits. Strong genetic correlations can greatly inhibit rapid responses to selection when it is acting on a multitude of traits simultaneously (Cheverud, 1984). The three traits we studied are directly related to fitness through pollinator attraction (flower size), pollination efficiency (tube length), and probability of self-pollination (antherstigma proximity), and therefore are expected to evolve together as suites of traits (Endler, 2000). Consequently, one would expect to find strong genetic correlations among them, as they are likely to have been under strong stabilizing selection over an extended period of time. Yet, we found only one significant correlation of moderate strength among the three floral characters investigated, which is surprising given the highly specialized pollination system of this species.

The moderate genetic correlations reported here might allow ready modification of these floral traits in $P$. drummondii and the generation of various new combinations of trait values. If these findings are representative to the species, they could also explain the association of large petals with short flower tubes in $P$. roemeriana (Wherry, 1955), which apparently evolved from a recent $P$. drummondii-like ancestor with longer flower tubes and smaller flower sizes (Ferguson et al, 1999). The presence of relatively weak genetic correlations among the three floral traits in this species is not unique, however. Genetic correlations among other floral traits also tend to be considerably lower than 0.5 (Schwaegerle et al, 1986; Schwaegerle and Levin, 1991; Waitt and Levin, 1993).

Given the relatively weak genetic correlations and the evolutionary lability of flower size in P. drummondii, it is not surprising that floral divergence has occurred even within the species. We found that the red-flowered race has on average larger flowers than the pink race. We argued elsewhere (Lendvai and Levin, unpublished) that this increase may have occurred to compensate for the disadvantage of the red color that is less attractive to pollinators than pink (Levin, 1972).

Other reproductive characters also have responded readily to selection in $P$. drummondii. Autogamous seed production in the primarily xenogamous $P$. drummondii was shifted by almost 10-fold from 5.1 to $56.2 \%$ in the Nixon population within only two generations. In the cultivar Salmon Beauty, the level of autogamy declined to $12.1 \%$ and increased to near $100 \%$ from the initial $53.9 \%$ after only two generations of bi-directional selection (Bixby and Levin, 1996). In another experiment, Fritz (1997) performed artificial selection for interspecific cross-incompatibility between $P$. drummondii and $P$. cuspidata that cross readily in the field. Relative hybrid seed set decreased by $15 \%$ and $36 \%$ in the two selected lines of $P$. drummondii after two generations of selection for low levels of cross-compatibility. From these studies it seems that $P$. drummondii has a great capacity to respond to natural selection in characters that are important in determining pollinator specificity and attractiveness (flower size, tube length), mating system (anther-stigma proximity, autogamous seed production), and reproductive barriers (cross-compatibility).

If present day pink-flowered $P$. drummondii populations are representative of the common ancestor of the annual clade in terms of its evolutionary capacities, then our results also can provide some insights into the evolutionary dynamics of the annual clade. Phylogenetic 
and comparative data suggest that the pink race of $P$. drummondii exhibits the largest number of plesiomorphic characters in the annual clade (Ferguson et al, 1999), and is likely to be the most representative of the presumed ancestor. A decrease in pollinator availability could have fostered increasing levels of autogamy and decreasing flower size in a $P$. drummondii-like ancestor leading relatively rapidly to the formation of $P$. cuspidata whose flowers are $35 \%$ smaller than those of $P$. drummondii. Alternatively, the evolution of $P$. roemeriana with flowers $20 \%$ larger than those of P. drummondii might have resulted from changes in the original pollinator fauna in relatively short evolutionary times. Larger flower size may have increased the reliability and effectiveness of pollinator service, for instance, as indicated by the number of pollen tubes in the pistils, which is on average 3-5 times higher than that in $P$. drummondii (Levin, unpublished). This species is one of the few in the genus that, unlike its closest relatives, has 3-5 ovules per locule. Since packaging many ovules in the same ovary is only a successful strategy if pollen receipt and fertilization rates are high, it is likely that a change in the pollinator fauna was a crucial factor in the evolution of this species.

We conclude that responsiveness to selection and moderate genetic correlations of reproductive traits in $P$. drummondii have largely contributed to the great evolutionary potential of the species. Evolutionary lability and weak genetic integration are likely to have played a crucial role also in the accumulation of the existing large phenotypic variation within the species, and in the process of differentiation in the annual lineage of Phlox.

\section{Acknowledgements}

We thank the indefatigable help of Dena Sutton in the greenhouse throughout the course of the experiment. We are also grateful for the comments and suggestions of Randy Linder, Michael Singer, Beryl Simpson, and the two anonymous reviewers for improving the manuscript. This work was supported by the Department of Botany, University of Texas at Austin.

\section{References}

Al-Hiyali SAK, McNeilly T, Bradshaw AD (1990). The effect of zinc contamination from electricity pylons. Contrasting patterns of evolution in five grass species. New Phytol 114: 183-190.

Bixby PJ, Levin DA (1996). Response to selection on autogamy in Phlox. Evolution 50: 892-899.

Böhle U-R, Hilger HH, Martin WF (1996). Island colonization and evolution of the insular woody habit in Echium L. (Boraginaceae). Proc Natl Acad Sci USA 93: 1174011745.

Bradshaw HD, Otto KG, Frewen BE, McKay JK, Schemske DW (1998). Quantitative trait loci affecting differences in floral morphology between two species of monkeyflowers (Mimulus). Genetics 149: 367-382.

Campbell DR (1996). Evolution of floral traits in a hermaphroditic plant: field measurements of heritabilities and genetic correlations. Evolution 50: 1442-1453.

Cheverud JM (1984). Quantitative genetics and developmental constraints on evolution by selection. J Theor Biol 110: 155171.
Conner J, Via S (1993). Patterns of phenotypic and genetic correlations among morphological and life-history traits in wild radish, Raphanus raphanistrum. Evolution 47: 704-711.

Cresswell JE (1998). Stabilizing selection and the structural variability of flowers within species. Ann Bot 81: 463-473.

Davies MS (1993). Rapid evolution in plant populations. In: Lees DR, Edwards D (eds) Evolutionary Patterns and Processes, Academic Press for The Linnean Society of London: London. pp. $171-188$.

Doebley J, Stec A (1993). Inheritance of the morphological differences between maize and teozinte: comparison of results for two $\mathrm{F}_{2}$ populations. Genetics 134: 559-570.

Endler JA (2000). Adaptive genetic variation in the wild. In: Mousseau TA, Sinervo B, Endler JA (eds) Adaptive Genetic Variation in the Wild, Oxford University Press: Oxford. pp. 251-260.

Ernst WHO, Verkleij JAC, Vooijs R (1983) Bioindication of a surplus of heavy metals in terrestrial ecosystems. Env Monit Assesss 3: 297-305.

Falconer DS, Mackay TFC (1996). Introduction to Quantitative Genetics, 4th ed. Longman: London.

Ferguson CJ, Krämer F, Jansen RK (1999). Relationships of eastern North American Phlox (Polemoniaceae) based on ITS sequence data. Syst Bot 24: 616-631.

Fisher RA (1930). The Genetical Theory of Natural Selection. Oxford University Press: Oxford.

Fritz JH (1997). Artificial Selection on Interspecific Crossing Barriers in Phlox. PhD Dissertation, University of Texas, Austin: pp 122.

Galen C (1996). Rates of floral evolution: adaptation to bumblebee pollination in an alpine wildflower, Polemonium viscosum. Evolution 50: 120-125.

Goldblatt P (1990). Phylogeny and classification of Iridaceae. Ann Mo Bot Gard 77: 607-627.

Goldblatt P, Manning JC (1996). Phylogeny and speciation in Lapeirousia subgenus Lapeirousia (Iridaceae, Ixoideae). Ann Mo Bot Gard 83: 346-361.

Grant V (1994). Modes and origins of mechanical and ethological isolation in angiosperms. Proc Natl Acad Sci USA 91: 3-10.

Grant VE, Grant KA (1965). Flower Pollination in the Phlox Family. Columbia University Press: New York.

Harrison CJ, Möller M, Cronk QCB (1999). Evolution and development of floral diversity in Streptocarpus and Saintpaulia. Ann Bot 84: 49-60.

Hodges SA, Arnold ML (1995). Spurring plant diversification: are floral nectar spurs a key innovation? Proc Royal Soc London B 262: 343-348.

Levin DA (1972). The adaptedness of corolla-color variants in experimental and natural populations of Phlox drummondii. Am Nat 106: 57-70.

Levin DA (2000). The Origin, Expansion, and Demise of Plant Species. Oxford University Press: Oxford.

Lynch M, Walsh B (1998). Genetics and Analysis of Quantitative Traits. Sinauer Associates: Sunderland, MA.

Macnair MR (1990). The potential for rapid speciation in plants. Genome 31: 203-210.

Mayr E (1970). Populations, Species, and Evolution. The Belknap Press of the Harvard University Press: Cambridge, MA.

Mazer SJ, Delesalle VA, Neal PR (1999). Responses of floral traits to selection on primary sexual investment in Spergularia marina: the battle between the sexes. Evolution 53: 717-731.

Mazer SJ, Meade DE (2000). Geographic variation in flower size in wild radish. The potential role of pollinators in population differentiation. In: Mousseau TA, Sinervo B, Endler JA (eds) Adaptive Genetic Variation in the Wild, Oxford University Press: Oxford, pp. 157-186. 
Meagher TR (1994). The quantitative genetics of sexual dimorphism in Silene latifolia (Caryophyllaceae). II. Response to sex-specific selection. Evolution 48: 939-951.

Orr HA (1998). The population genetics of adaptation: the distribution of factors fixed during adaptive evolution. Evolution 52: 935-949.

Proctor M, Yeo P, Lack A (1996). The Natural History of Pollination. The Timber Press: Portland, OR.

Reeves PA, Olmstead RG (1998). Evolution of novel morphological and reproductive traits in a clade containing Antirrhinum majus (Scrophulariaceae). Am J Bot 85: 10471056.

Schwaegerle KE, Garbutt K, Bazzaz FA (1986). Differentiation among nine populations of Phlox. I. Electrophoretic and quantitative variation. Evolution 40: 506-517.

Schwaegerle KE, Levin DA (1991). Quantitative genetics of fitness traits in a wild population of Phlox. Evolution 45: 169-177.

Soltis PS (1986). Estimates of heritability and genetic correlations of morphometric traits in Clarkia (Onagraceae). Theor Appl Genet 73: 88-93.
Stanton ML, Young HJ (1994). Selecting for floral character associations in wild radish, Raphanus sativus L. J Evol Biol 7: 271-285.

Stebbins GL (1974). Flowering Plants. Evolution Above the Species Level. The Belknap Press of the Harvard University Press: Cambridge, MA.

Waitt DE, Levin DA. (1993). Phenotypic integration and plastic correlations in Phlox drummondii Hook. (Polemoniaceae). Am J Bot 80: 1224-1233.

Wherry ET (1955). The Genus Phlox. Morris Arboretum Monographs III. Philadelphia, PA.

Worley AC, Barrett SC (2000). Evolution of floral display in Eichhornia paniculata (Pontederiaceae): direct and correlated responses to selection on flower size and number. Evolution 54: 1533-1545.

Young HJ, Stanton ML, Ellstrand NC, Cleggs JM (1994). Temporal and spatial variation in heritability and genetic correlations among floral traits in Raphanus sativus, wild radish. Heredity 73: 298-308. 